John Carroll University

Carroll Collected

2020

A Spatiotemporal Assessment of Dietary Partitioning between Color Morphs of a Terrestrial Salamander

Maggie M. Hantak

Kyle M. Brooks

Cari-Ann M. Hickerson

Carl D. Anthony

Shawn R. Kuchta

Follow this and additional works at: https://collected.jcu.edu/fac_bib_2020

Part of the Biology Commons 


\title{
A Spatiotemporal Assessment of Dietary Partitioning between Color Morphs of a Terrestrial Salamander
}

\begin{abstract}
When color pattern variation is co-adapted with other biological features, distinct color morphs may be separated along divergent niche axes, and data on niche partitioning can provide insight into how distinct color morphs are maintained over spatiotemporal scales. The Eastern Red-backed Salamander, Plethodon cinereus, contains two common color morphs (striped and unstriped) that differ along several trait axes in addition to coloration. Previous studies from a single population have suggested that dietary composition represents an important axis of ecological differentiation between morphs of $\boldsymbol{P}$. cinereus. To determine if morphs partition prey resources over space and time, we collected stomach contents from morphs across six populations that ranged in color morph frequency from $100 \%$ striped to $>\mathbf{9 9} \%$ unstriped, and sampled each population in a spring and a fall season. From each population and season, we also sampled leaf litter invertebrates to quantify morph differences in prey selection. Based on previous studies, we predicted striped morph diet would consist of higher quality prey in polymorphic populations, whereas in monomorphic populations, we predicted both morphs would have a more variable diet due to ecological release from intermorph competition. In the two polymorphic populations we examined, one showed no evidence of diet differences and the other mirrored differences reported from previous studies. There was no change in dietary breadth between polymorphic and monomorphic populations, and thus no signature of dietary release. Our results show there is a high degree of overlap between dietary and leaf litter invertebrates, suggesting both morphs of $\boldsymbol{P}$. cinereus are generalist predators. Finally, we found dietary composition varied across seasons and populations, which demonstrates the importance of examining morph traits over spatial and temporal scales.
\end{abstract}

C

OLOR polymorphisms, where multiple distinct color phenotypes coexist within a population, are common in nature (Ford, 1945; Gray and McKinnon, 2007; McLean and Stuart-Fox, 2014). Color polymorphic species, which contain co-adapted sets of traits, are known as 'morphs' (Sinervo and Svensson, 2002; McKinnon and Pierotti, 2010). Quantifying differences between morphs can elucidate the degree of ecological separation within a population and provides information on how selection might operate on morphs. In contrast, a lack of partitioning of critical resources such as food or territories may result in strong competition between morphs, which under some circumstances can lead to the fixation of one morph within a population (West-Eberhard, 1986; Svensson et al., 2001; Comendant et al., 2003). Polymorphism is important to understand because it informs us about the origin of ecologically relevant differences in form and behavior, including species formation (Sinervo and Svensson, 2002).

Polymorphic species commonly have widespread geographic distributions; however, little work has focused on the coevolutionary interactions between morphs within a geographic context (but see Thompson, 2005; Davis-Rabosky et al., 2016; Holmes et al., 2017; Evans et al., 2018). Selection and evolutionary change vary through space and time as a consequence of local ecological conditions, and suites of coadapted traits may vary across the range of a species (Brodie et al., 2002; Thompson, 2005; Corl et al., 2010). Accordingly, a better understanding of the ecological differences between morphs may benefit from spatiotemporal replication.
The Eastern Red-backed Salamander, Plethodon cinereus, has a widespread distribution within the northeastern United States and is color polymorphic throughout portions of its range (Petranka, 1998; Moore and Ouellet, 2015). There are two common morphs in this species: a striped morph with a red stripe overlaid on a black dorsum and an unstriped morph that has a completely black dorsum (Highton, 1959; Moore and Ouellet, 2014). The morphs, which have a genetic basis with no intermediate phenotypes, have a broad geographic range (Highton, 1959, 1975; Moore and Ouellet, 2015). The ecological and evolutionary dynamics involved in maintaining the polymorphism are not well understood, yet the morphs seem to differ along several biological axes, including physiology, mating interactions, territoriality, and dietary composition (Lotter and Scott, 1977; Moreno, 1989; Gibbs and Karraker, 2006; Acord et al., 2013; Anthony and Pfingsten, 2013; Reiter et al., 2014; Jaworski et al., 2018). However, most studies of dietary morph divergence have been conducted without replication over space and time.

Diet has been hypothesized to be an important axis of niche differentiation separating many morphs in nature (Price, 1987; Schluter and McPhail, 1992; Karpestam and Forsman, 2011). Individuals of $P$. cinereus defend territories that contain valuable resources, including prey (Mathis, 1990, 1991). While P. cinereus is a generalist predator (Burton, 1976; Maerz et al., 2005; Bondi et al., 2019), studies have found that individuals with established territories, which are aggressively defended, consume prey that maximize their caloric yield (Jaeger and Barnard, 1981; Jaeger et al., 1981). In 


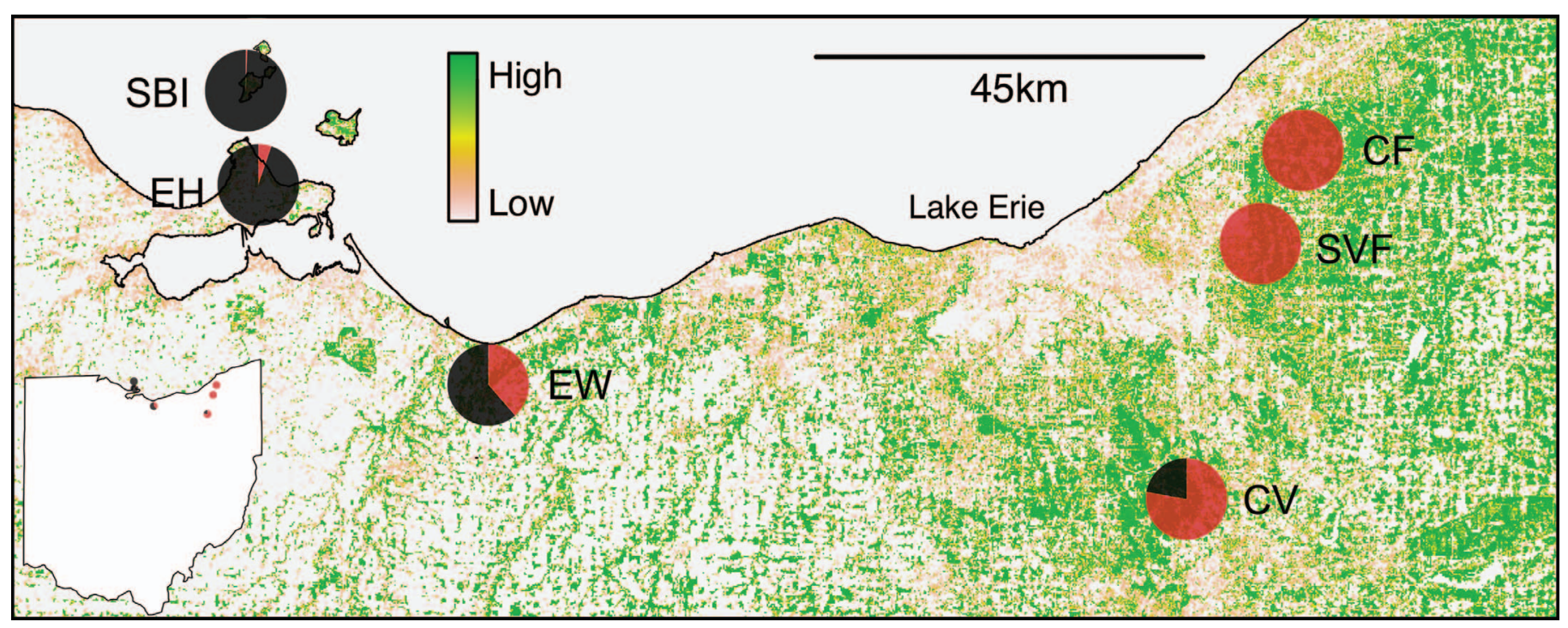

Fig. 1. Map of study sites on a percent canopy cover landscape surface in northern Ohio. Color morph frequencies (black $=$ unstriped, red $=$ striped). From west to east: South Bass Island (SBI), East Harbor State Park (EH), Edison Woods (EW), Manatoc Scout Reservation near Cuyahoga Valley (CV), Squire Valleevue Farm (SVF), and Chapin Forest (CF).

a polymorphic population, an experimental study found that striped morphs are dominant territory holders compared to unstriped morphs and will expel intruders from cover objects (Reiter et al., 2014). In addition, Anthony et al. (2017) found that unstriped morphs occupy territories that have lower prey richness than striped morphs. Finally, previous studies in one polymorphic population suggested that striped individuals were able to gain more access to small, softbodied, easily digestible prey (i.e., high quality prey; Jaeger, 1990), relative to unstriped individuals (Anthony et al., 2008; Stuczka et al., 2016).

In the current study, we investigated dietary prey composition of the striped and unstriped morphs of $P$. cinereus across two seasons. We included six geographically distinct populations that vary in morph frequency, from $100 \%$ striped to polymorphic to $>99 \%$ unstriped (Fig. 1). We hypothesized that morphs would partition dietary resources within polymorphic populations, facilitating the maintenance of the polymorphism, but that dietary breadth in monomorphic sites would be wider. Following from previous studies (Mathis, 1990; Anthony et al., 2008, 2017; Paluh et al., 2015; Reiter et al., 2014; Stuczka et al., 2016), we also predicted that striped morphs would have access to and consume a higher diversity of invertebrate prey that are more energetically profitable compared to unstriped morphs.

\section{MATERIALS AND METHODS}

Dietary and habitat data were collected in both the spring and fall of 2014 from six populations in northern Ohio that vary in morph frequency: Squire Valleevue Farm (SVF; 100\% striped); Chapin Forest Reservation (CF; 100\% striped); Manatoc Scout Reservation, directly adjacent to Cuyahoga Valley National Park (CV; 80\% striped); Edison Woods Reservation (EW; $45 \%$ striped); the Heineman property on South Bass Island (SBI; $<1 \%$ striped; Hantak et al., 2015); and East Harbor State Park (EH; 8\% striped; Fig. 1, Table 1). All sites are composed of unmanaged, secondary, hardwood forests (ODNR, 2019).
We collected salamanders at dawn, $\geq 48$ hours following rainfall events (Hantak et al., 2016). Salamanders were collected from under rocks and logs within an area $\leq 2$ hectares at each site. Data on morph type, sex, snout-vent length (SVL), and diet were collected from the first 15 adult ( $\geq 32 \mathrm{~mm} \mathrm{SVL}$ ) salamanders of each color morph captured in the spring and fall (Table 1). In populations with a high frequency of one color morph (SVF, CF, SBI, EH), data were only collected from the common morph; therefore, diet data were collected from a total of 240 salamanders (Table 1). Stomach samples were collected using gastric lavage, a nonlethal method that has been shown to effectively remove the stomach contents of plethodontid salamanders (Legler and Sullivan, 1979; Bondi et al., 2015; Hantak et al., 2016). Subsequently, individuals were replaced to their original point of capture. Dietary samples from each individual were stored in $70 \%$ ethanol.

To determine if salamanders non-randomly selected certain prey types from their environment and if morphs differed in their selection of prey from the available pool of potential prey items, leaf litter invertebrates were collected. Dietary and leaf litter samples were collected on the same day at each site during the spring and fall, totaling 12 sampling dates (Table 1). This sampling scheme aided in avoiding resampling and minimizing the effects of climatic variation. Within each study location, leaf litter was collected from the area adjacent to the last three salamanders captured. We hand collected enough leaf litter (Oi and Oe soil horizons) to fill a gallon sized bag from each of the three areas, totaling three bags of leaf litter per site and season. Invertebrates were obtained by placing leaf litter in Berlese funnels and Winkler extraction bags (Ivanov and Keiper, 2009) for 72 hours. Collected leaf litter invertebrates were stored in $70 \%$ ethanol.

For each stomach and leaf litter sample, invertebrates were sorted into morphospecies (i.e., presumed distinct species based on morphology), counted, and identified to the lowest taxonomic category (usually order or class) with a dissecting stereomicroscope. Using an ocular micrometer, the length and width of each dietary invertebrate was recorded to the 
Table 1. Sampling date information for salamander stomach contents and leaf litter collection from each site (with \% striped morph frequency/site). Striped sites include Chapin Forest (CF) and Squire Valleevue Farm (SVF). Polymorphic sites include Manatoc Scout Reservation near Cuyahoga Valley (CV) and Edison Woods (EW). Unstriped sites include East Harbor State Park (EH) and South Bass Island (SBI). Sample size ( $n$ ) of salamander dietary samples of each morph are included, as well as temperature during sampling, percent humidity, and snout-vent length (SVL) range of salamanders per site and date.

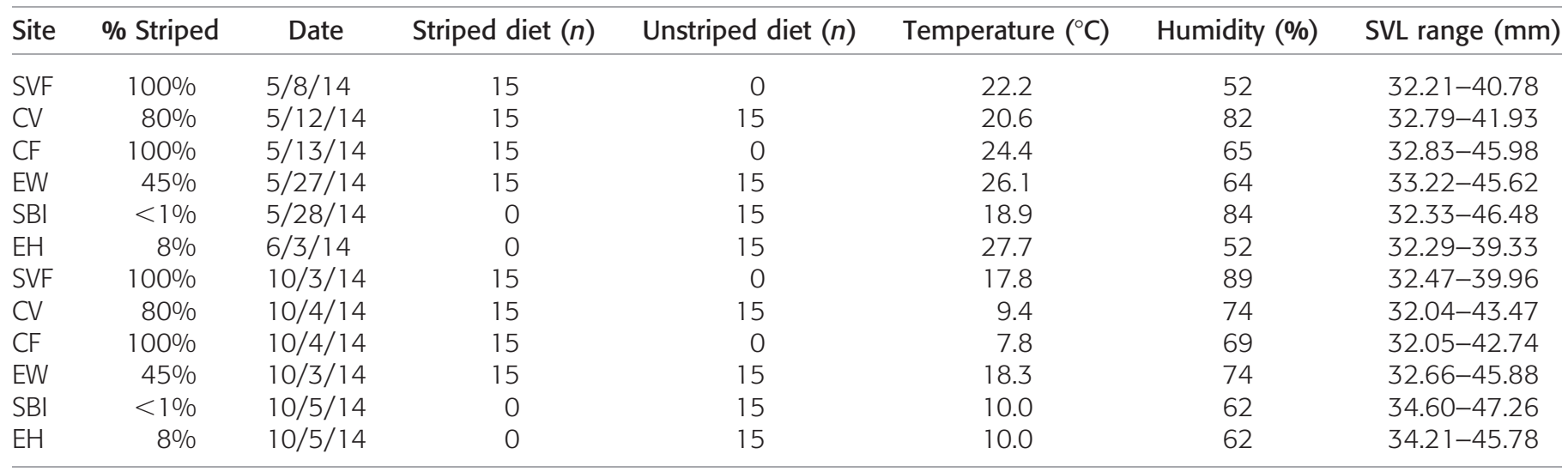

nearest $0.01 \mathrm{~mm}$. Total dietary volume in each salamander was estimated using the equation for a prolate spheroid (Dunham, 1983):

$$
\frac{4 \pi}{3}\left(\frac{\text { length }}{2}\right)\left(\frac{\text { width }}{2}\right)^{2}
$$

To determine if the number of salamanders provided an accurate estimate of diet from each morph and population, we constructed species accumulation curves. We ran a permutational multivariate analysis of variance (PERMANOVA) to test for group mean differences in dietary composition across season, site, and morph. Significance was assessed using the pairwiseAdonis package in R (Martinez, 2019), and to illustrate dietary variation, we employed non-metric multidimensional scaling (NMDS). PERMANOVA and NMDS were based on Jaccard dissimilarity indices (Oksanen et al., 2016) and were run on morphospecies data. Total number and volume of dietary prey were log-transformed, and zero values were removed to fulfill assumptions of normality. We used full factorial ANOVAs to test for season, site, and morph differences in the total number and volume of prey consumed by salamanders. Dietary niche breadth for each individual was calculated with the Shannon diversity index for each season. We used a full factorial ANOVA to test for season, site, and color morph differences in dietary niche breadth. A test of homogeneity of multivariate group dispersions (PERMDISP) was used to examine variance in invertebrate breadth between leaf litter and salamander diet for each season, site, and morph. PERMDISP is a multivariate equivalent to the Levene's test and uses distance matrices to estimate the mean distance to group centroids (Anderson, 2006). We used Tukey's HSD post hoc tests to examine pairwise differences. Statistical analyses were conducted in vegan (Oksanen et al., 2016) using $\mathrm{R}$ statistical software ( $\mathrm{R}$ Core Team, 2018).

To test if morphs in the polymorphic populations $\mathrm{CV}$ and EW differ in diet, we calculated importance values $\left(I_{x}\right)$ for each taxonomic prey category for each salamander using:

$$
I_{x}=\left[\left(n_{x} / N\right)+\left(v_{x} / V\right)+\left(f_{x} / F\right)\right] / 3
$$

where $n_{x}, v_{x}$, and $f_{x}$ represent the number, volume, and frequency (the number of individuals that consumed that prey item) of each prey category and $N, V$, and $F$ denote the sum of each value across all stomachs from a population. Importance values range from 0 to 1 , with higher values equaling more important prey (Powell et al., 1990; Anderson and Mathis, 1999). Numbers of the six most important prey items were compared between morphs using chi-square tests within each season.

\section{RESULTS}

We identified 2,314 dietary prey items from 240 individuals of $P$. cinereus during spring and fall of 2014. Species accumulation curves demonstrate that sample sizes from each morph and population provided an accurate assessment of diet (Supplemental Fig. 1; see Data Accessibility). Spring salamanders $(n=120)$ consumed 1,441 prey, whereas fall individuals $(n=120)$ consumed 873 prey. Invertebrates were found from 21 taxonomic categories (class, order, or family) and totaled 51 morphospecies (Supplemental Table 1; see Data Accessibility). Spring individuals consumed a mean number of $11.91 \pm 14.67 \mathrm{SD}$ prey, and fall salamanders consumed a mean of $7.16 \pm 5.39 \mathrm{SD}$ prey (Table 2 ). In the spring, the frequency of occurrence of dietary invertebrates largely consisted of Acari (mites; 29\%), Collembola (springtails; 23\%), and Formicidae (ants; 15\%). Fall salamander diet primarily consisted of Formicidae (31\%), Acari (17\%), and Collembola (12\%).

We found no effect of morph on group mean differences of dietary prey composition (i.e., morphospecies) when accounting for season and site (Table 3). However, the interaction between season and site was significant (Table 3 ); therefore, we looked at population differences within each season and found significant dietary variation within both the spring and fall (Table 3). Sex and SVL were not important factors for our hypotheses or in the full model (not shown) and thus were eliminated from the final model. Dietary differences within each season are illustrated using NMDS of community dissimilarities with 95\% confidence ellipses for population centroids (Fig. 2). Pairwise comparisons of $P$-values, which were adjusted for multiple comparisons, in the spring reveal that the western sites SBI (U), EH $(\mathrm{U})$, and EW (S/U) overlapped in dietary prey composition, 
Table 2. Mean number ( $n)$ and volume (V) each with standard deviation (SD) of prey consumed from each site, morph, and season.

\begin{tabular}{|c|c|c|c|c|c|c|}
\hline Site & Morph & Season & Mean $n$ & $\mathrm{SD} n$ & Mean V & SD V \\
\hline SVF & Striped & Spring & 23.4 & 32.69 & 4.17 & 2.92 \\
\hline SVF & Striped & Fall & 6.27 & 5.95 & 9.44 & 18.02 \\
\hline $\mathrm{CF}$ & Striped & Fall & 11.4 & 9.69 & 22.24 & 22.93 \\
\hline $\mathrm{CV}$ & Striped & Spring & 14.13 & 8.55 & 13.78 & 10.96 \\
\hline $\mathrm{CV}$ & Striped & Fall & 5.94 & 3.62 & 4.6 & 4.94 \\
\hline EW & Striped & Spring & 8.27 & 11.93 & 9.99 & 8.46 \\
\hline EW & Striped & Fall & 5.47 & 3.58 & 12.27 & 12.25 \\
\hline EW & Unstriped & Spring & 9.07 & 8.86 & 16.24 & 11.48 \\
\hline EW & Unstriped & Fall & 6 & 4.16 & 8.36 & 9.48 \\
\hline $\mathrm{EH}$ & Unstriped & Spring & 8.53 & 5.57 & 9.37 & 6.23 \\
\hline $\mathrm{EH}$ & Unstriped & Fall & 9.2 & 4.54 & 17.56 & 9.19 \\
\hline
\end{tabular}

but these sites did not overlap with any of the three eastern populations, CF (S), CV (S/U), or SVF (S). In addition, SVF overlapped in diet with CF and CV. Dietary composition of CV salamanders also overlapped with EW salamander diets. All other site comparisons of prey composition in the spring differed (Fig. 2A, Supplemental Table 2; see Data Accessibility). In the fall, SVF dietary composition overlapped with $\mathrm{EH}$, $\mathrm{EW}, \mathrm{CV}$, and CF. In addition, dietary prey in EH overlapped with that of SBI, EW, and CV. All other site comparisons of salamander dietary prey composition in the fall differed (Fig. 2B, Supplemental Table 2; see Data Accessibility). Across seasons and sites, morphs did not differ in the total number of dietary prey consumed (Table 3). Total volume of consumed prey differed by season, site, and morph (Table $3)$. Within seasons, there was no interaction between site and morph in the spring or fall; however, salamanders differed in

Table 3. Results of (A) PERMANOVA for the full model, as well as seasonal and site effects. Full factorial ANOVA results for (B) the total number of invertebrates consumed, (C) the total volume of consumed prey, and (D) dietary niche breadth for model variations of season, site, and morph effects. Significant results in bold.

\begin{tabular}{lccr}
\hline Model & df & $F$ & \multicolumn{1}{c}{$P$} \\
\hline (A) PERMANOVA & & & \\
$\quad$ Season x Site x Morph & 1,241 & 0.72 & 0.758 \\
$\quad$ Season x Site & 5,241 & 2.38 & $<0.001$ \\
$\quad$ Spring: Site & 5,119 & 3.64 & $<0.001$ \\
$\quad$ Fall: Site & 5,119 & 2.84 & $<0.001$ \\
(B) Total number (ANOVA) & & & \\
$\quad$ Season x Site x Morph & 1,217 & 2.03 & 0.156 \\
(C) Total volume (ANOVA) & & & \\
$\quad$ Season x Site x Morph & 1,217 & 4.67 & 0.032 \\
$\quad$ Spring: Site x Morph & 1,110 & 2.52 & 0.115 \\
$\quad$ Spring: Site & 5,110 & 2.51 & 0.034 \\
$\quad$ Fall: Site x Morph & 1,107 & 2.17 & 0.144 \\
$\quad$ Fall: Site & 5,107 & 4.54 & $<0.001$ \\
(D) Niche breadth (ANOVA) & & & \\
$\quad$ Spring: Site x Morph & 1,112 & 0.59 & 0.446 \\
$\quad$ Spring: Site & 5,112 & 3.60 & 0.005 \\
$\quad$ Fall: Site x Morph & 1,112 & 0.23 & 0.634 \\
$\quad$ Fall: Site & 5,112 & 0.43 & 0.119 \\
\hline
\end{tabular}

prey volume by site (Table 3). In the spring, pairwise comparisons reveal that salamanders in EW contained a higher prey volume than SVF salamanders. In the fall, pairwise comparisons revealed that EH salamanders contained a higher prey volume than CV and SVF.

In the spring, we identified a total of 4,464 leaf litter invertebrates, whereas in the fall we identified 3,959 leaf litter invertebrates. Across seasons, Acari and Collembola were the most abundant leaf litter invertebrates at each site (Supplemental Fig. 2; see Data Accessibility). Dietary and leaf litter invertebrate breadth largely overlapped, and most comparisons did not differ (Supplemental Table 3; see Data Accessibility). Salamander prey composition differed from leaf litter invertebrates at $\mathrm{EW}$ in the spring $\left(F_{2,30}=5.57, P=\right.$ $0.009)$. Breadth of invertebrate morphospecies collected from leaf litter was greater than the breadth of dietary invertebrates of striped $(P=0.007)$ and unstriped $(P=0.014)$ salamanders. These results suggest that salamanders at EW consumed a subset of available prey; however, morphs overlapped in diet $(P=0.861 ;$ Fig. 3A). In the spring, salamander diet and leaf litter invertebrates also differed at SBI $\left(F_{1,15}=5.00, P=0.040\right)$, with higher invertebrate variance in the leaf litter compared to salamander diet (Fig. 3B, Supplemental Table 3; see Data Accessibility). Estimates of niche breadth did not differ by site and morph in the spring or fall, but differed by site in the spring with EW having a lower niche breadth than CV (Table 3, Fig. 4). The six most important prey for $P$. cinereus at $\mathrm{CV}$ and EW included Acari, Coleoptera, Collembola, Hymenoptera, larvae of Lepidoptera, and Oligochaeta (Table 4). Important prey did not differ between striped and unstriped morphs from CV in the spring $\left(\mathrm{df}=5, X^{2}=1.0, P=0.961\right)$, but there was a trend in the fall $\left(\mathrm{df}=5, X^{2}=10.7, P=0.058\right)$. Striped and unstriped morphs from EW did not differ in important prey in the spring ( $\mathrm{df}=$ $\left.5, X^{2}=2.6, P=0.737\right)$, or fall $\left(\mathrm{df}=5, X^{2}=7.3, P=0.199\right.$; Table $4)$.

\section{DISCUSSION}

Discrete morphs are composed of co-adapted sets of traits and differ in elements of their biology in addition to color, including physiology, behavior, and other morphological characters (Sinervo and Svensson, 2002; McKinnon and 

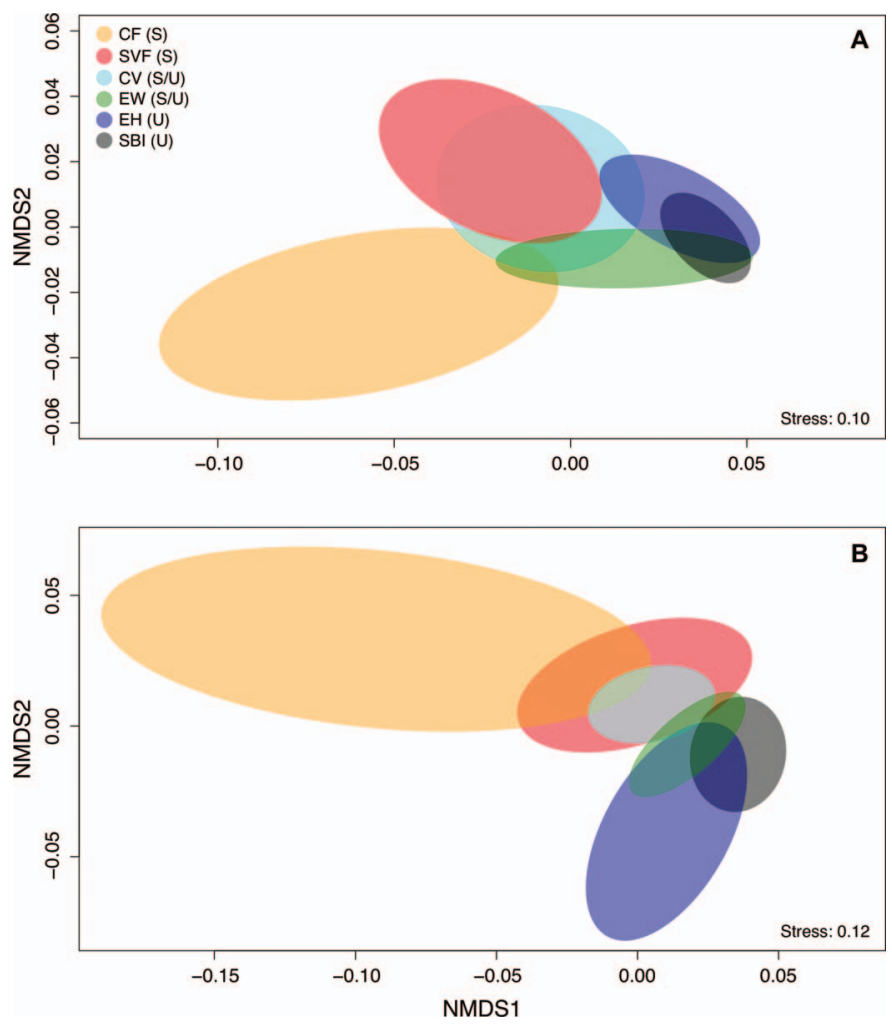

Fig. 2. Non-metric multidimensional scaling (NMDS) plots with $95 \%$ confidence ellipses of diet variance based on morphospecies for each population in the (A) spring and (B) fall. Striped sites include Chapin Forest (CF; S) and Squire Valleevue Farm (SVF; S). Polymorphic sites include Manatoc Scout Reservation near Cuyahoga Valley (CV; S/U) and Edison Woods (EW; S/U). Unstriped sites include East Harbor State Park $(\mathrm{EH} ; \mathrm{U})$ and South Bass Island $(\mathrm{SBI} ; \mathrm{U})$. More overlap indicates greater dietary similarity.

Pierotti, 2010). Morph traits at a single site are often thought to parallel other populations across the range of a species; however, it is well known that local species interactions and environmental conditions can result in geographically variable patterns of evolution (Thompson, 2005; McLean and Stuart-Fox, 2014). In this study, we examined the dietary composition of the striped and unstriped color morphs of $P$. cinereus across two seasons and six populations that varied in morph frequency. Our data do not support the hypothesis that dietary partitioning characterizes the two color morphs, as the diet of the morphs overlapped in prey type, number, and volume. Important dietary prey did not differ between morphs in the polymorphic EW site or at CV in the spring; however, in the fall there was a trend for morphs at CV to differ in important prey. Overlap in dietary and leaf litter invertebrates suggests individuals of $P$. cinereus are generalist predators; however, individuals at SBI and EW consumed a subset of the prey available in the leaf litter. No change in dietary niche breadth between monomorphic and polymorphic populations suggests a lack of ecological release when a morph is lost. Dietary composition varied across seasons and sites, demonstrating the importance of studying ecological attributes over spatial and temporal scales.

In the current study, while taking into consideration spatial and temporal effects, we predicted morphs of $P$. cinereus would differ in diet, where striped morphs would consume more energetically profitable prey compared to
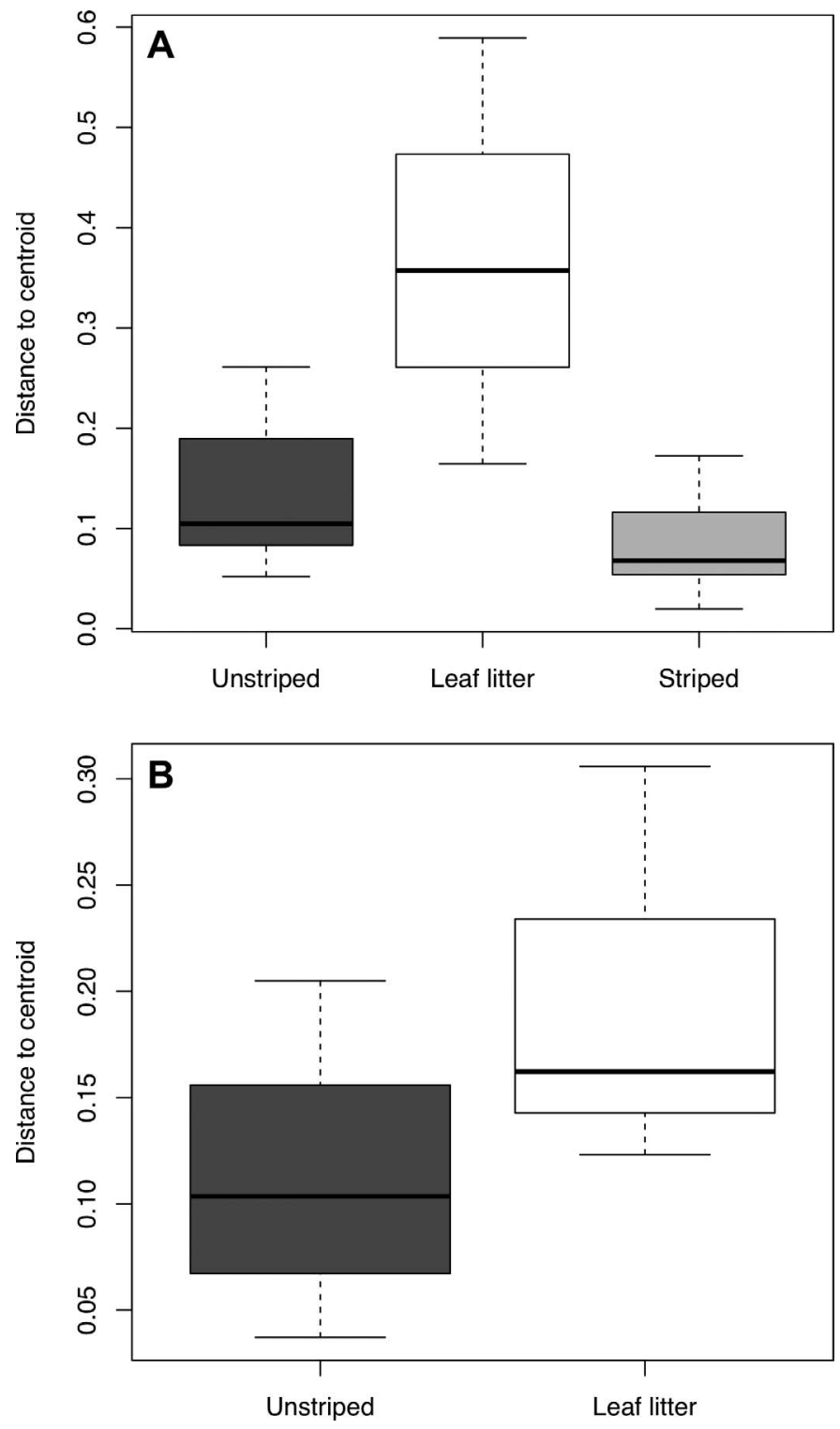

Fig. 3. (A) Edison Woods (EW) salamander color morph and leaf litter invertebrate breadth in the spring season. (B) South Bass Island (SBI) salamander and leaf litter invertebrate breadth in the spring season.

unstriped morphs. Instead, our results demonstrate that the diets of the two morphs overlap. These results were unexpected, as prior studies found the morphs differed in dietary composition (Anthony et al., 2008; Paluh et al., 2015; Stuczka et al., 2016). However, some findings across these earlier studies varied. For instance, Anthony et al. (2008) and Stuczka et al. (2016) found that striped morph diet was composed of higher quality prey (e.g., Collembola), whereas Paluh et al. (2015) found that striped morphs consumed more ants than unstriped morphs, which are higher in chitin and less energetically profitable than many other invertebrates (Jaeger, 1990); however, this study only examined variation in ant prey species, and it may be possible that striped morphs consumed other, higher quality prey. Discordant results were also found concerning which morph consumed a higher diversity of dietary prey, with Anthony et al. (2008) finding that striped morph diet was more diverse, while Stuczka et al. (2016) found that the unstriped 
Table 4. (A) Spring and (B) fall importance values $\left(I_{x}\right)$ for the six dominant prey categories in striped and unstriped morph stomachs within the polymorphic CV and EW sites. Importance values were calculated from the total number $\left(n_{x}\right)$, volume $\left(v_{x}\right)$, and frequency $\left(f_{x}\right)$, shown in parentheses for each prey type, respectively.

\begin{tabular}{|c|c|c|c|c|}
\hline \multicolumn{5}{|l|}{ (A) Spring } \\
\hline Prey taxon & CV (striped) & CV (unstriped) & EW (striped) & EW (unstriped) \\
\hline Acari & $0.384(58,2.7,13)$ & $0.411(39,1.4,14)$ & $0.205(42,1.5,4)$ & $0.268(54,1.9,6)$ \\
\hline Collembola & $0.231(19,0.5,9)$ & $0.198(17,0.3,7)$ & $0.080(5,0.1,3)$ & $0.104(6,0.1,4)$ \\
\hline Hymenoptera & $0.384(43,30.7,12)$ & $0.332(33,25.6,9)$ & $0.250(22,16.0,7)$ & $0.270(24,24.6,8)$ \\
\hline Lepidoptera larvae & $0.290(8,75.9,7)$ & $0.213(5,57.5,4)$ & $0.251(5,67.0,4)$ & $0.183(5,59.8,4)$ \\
\hline Prey taxon & CV (striped) & CV (unstriped) & EW (striped) & EW (unstriped) \\
\hline Acari & $0.217(13,1.0,8)$ & $0.250(23,0.8,8)$ & $0.179(11,0.3,6)$ & $0.310(29,0.8,9)$ \\
\hline Coleoptera & $0.148(5,5.8,5)$ & $0.252(11,11.7,8)$ & $0.340(10,79.6,7)$ & $0.317(13,42.7,7)$ \\
\hline Collembola & $0.274(24,0.6,9)$ & $0.239(19,1.2,8)$ & $0.106(4,24.7,10)$ & $0.078(3,0.1,3)$ \\
\hline
\end{tabular}

diet was composed of a higher diversity of prey. Each of these studies took place in the same polymorphic population in northeast Ohio (our CV site). Differences between studies can be explained by discordant time scales, sampling techniques, and sample sizes. For instance, Anthony et al. (2008) collected dietary data from $P$. cinereus on a single day in a fall season, while Stuczka et al. (2016) collected stomach contents from $P$. cinereus over 13 months. In this study, samples were collected in a single day per site during a spring and a fall season. Variation in dietary composition in the CV site may reflect temporal changes in prey availability due to alterations in leaf litter mass and moisture, which may alter the dynamics of the local social environment (Walton, 2013).

Our finding of dietary overlap between the morphs was unexpected, as they differ in many other elements of their biology. For instance, a number of studies have suggested that the striped morph is more common in cooler and wetter habitats than the unstriped morph (Lotter and Scott, 1977; Gibbs and Karraker, 2006; Cosentino et al., 2017; but see

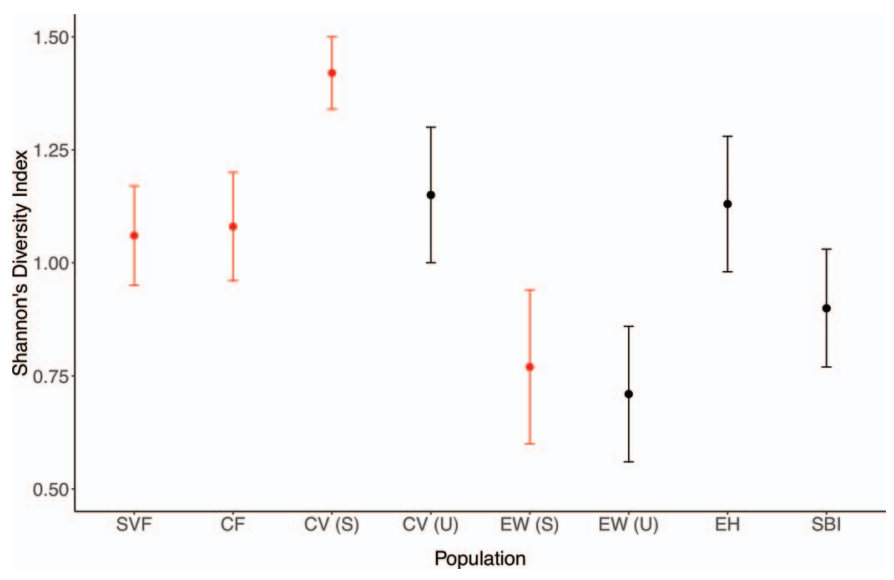

Fig. 4. Mean dietary niche breadth for each morph and population for the spring season, measured by the Shannon diversity index. Red represents striped morphs (S), black represents unstriped morphs (U). Error bars denote standard error of the mean.
Moore and Ouellet, 2015), and that the unstriped morph withdraws into underground retreats sooner with the onset of cold weather (Lotter and Scott, 1977; Moreno, 1989; Anthony et al., 2008). Studies have also shown that the morphs differ in response to predators, including differences in tail breakage frequencies (Moreno, 1989; Venesky and Anthony, 2007; Grant et al., 2018) and behavioral responses to predators (Venesky and Anthony, 2007; Otaibi et al., 2017). One study found that the striped morph exhibited higher levels of territorial behavior and aggression compared to the unstriped morph (Reiter et al., 2014). The unstriped morph has a lower metabolic rate, higher stress levels, and increased incidence of disease (Moreno, 1989; Petruzzi et al., 2006; Fisher-Reid et al., 2013; Venesky et al., 2015). In addition, in one population in Ohio (our CV site), males and females were found to pair assortatively by color (Anthony et al., 2008; Acord et al., 2013). These previous studies provide evidence that the morphs are composed of correlated trait complexes; however, as with our results on dietary composition, re-analysis of previous findings within a geographic context may help elucidate whether morph trends are consistent over spatiotemporal scales.

A study by Hantak and Kuchta (2018) found that the striped morph was better camouflaged than the unstriped morph against multiple backgrounds across three populations and two seasons. It is possible that decreased detection of striped morphs by visual predators affords greater foraging opportunities. However, we found no evidence that striped morphs consumed a greater number or volume of dietary prey. A similar prediction was made by Hantak et al. (2016), where the authors postulated that a rare erythristic (orangered) morph of $P$. cinereus, which may be a mimic of the toxic Eastern Newt (Notophthalmus viridescens; Kraemer and Adams, 2013), would have greater foraging opportunities than sympatric striped morphs and, therefore, consume more profitable prey. However, Hantak et al. (2016) found no difference in dietary composition between sympatric erythristic and striped morphs. Plethodon cinereus is known to be a generalist predator (Burton, 1976; Maerz et al., 2005; Bondi et al., 2019), and therefore, if dietary resources are plentiful, 
competition may not occur. However, during certain times of the year, such as during periods of unfavorable weather conditions (e.g., extreme dry periods) or periods of high activity, competition may be more intense (Pianka, 1974). It may be that our sampling took place during times of the year when competition for resources was relatively low. For example, our study was conducted in late spring and early fall shortly after rainfall events and may not coincide with periods of food limitation (Anthony and Pfingsten, 2013). It is also possible that our sampling was biased towards more territorial individuals. In all studies of diet in $P$. cinereus, including this study, individuals collected for dietary analyses were found under cover objects, which are thought to constitute high quality territory (Jaeger, 1980; Gabor, 1995). Such sampling schemes may have captured the most territorial unstriped individuals, even though striped individuals are considered the most territorial (Reiter et al., 2014). Future studies should investigate whether there is a territorymediated difference in diet by comparing individuals captured under cover objects with individuals found in the leaf litter.

Important prey $\left(I_{x}\right)$ also did not differ between morphs in our sampled polymorphic populations (CV and EW). However, there was a trend for important prey to differ between morphs in $\mathrm{CV}$ during the fall season $(P=0.058)$. Higher levels of sampling at $\mathrm{CV}$ in previous studies found that the diet of morphs differs seasonally (Stuczka et al., 2016), in the number of consumed prey (Anthony et al., 2008), and in the available prey in territories (Paluh et al., 2015; Anthony et al., 2017). Thus, the current results corroborate previous findings at $\mathrm{CV}$, although more subtle differences were not apparent in this study due to our smaller sample sizes within populations. In our case, the logistical constraints of including multiple populations constrained our withinpopulation sampling, meaning that large effects were needed for a high probability of detection. Such discrepancies between studies highlights the consideration of sample size and effect size when looking for differences between groups. Studies of single populations allow for the detection of fine distinctions, but risk missing important patterns present only at larger temporal or spatial scales (e.g., Thompson, 2005).

Across sites, non-random consumption of leaf litter invertebrates by salamanders occurred at SBI and EW in the spring. At the polymorphic EW site, both morphs consumed a subset of available prey, which could result in competition in this population if those prey resources are limited. However, we found no morph differences in dietary niche breadth, including no change in dietary breadth between polymorphic and monomorphic populations. Thus, in contrast with our a priori predictions, there is no evidence of ecological release in diet in monomorphic populations. In polymorphic populations, some prey may be less accessible to a subordinate morph when there is strong competition for food or territories. This competition can result in ecological character displacement, which, in part, may contribute to divergence between polymorphic and monomorphic populations. For example, Adams (2000) demonstrated that individuals of $P$. cinereus and $P$. hoffmani consume similar prey in allopatry, while in sympatry their diets differ. This sympatric divergence was associated with a corresponding shift in body size and head shape. Morphological character displacement has been found between other salamander species (Adams et al., 2007; Adams, 2010; Deitloff et al.,
2013), as well as in lizards in the genus Anolis (Schoener, 1970; Losos, 1990), the stickleback fish (Schluter and McPhail, 1992), and Darwin's finches (Grant and Grant, 2006). No studies have investigated morphological character displacement between color morphs in P. cinereus; however, such studies would help elucidate the role of competition.

Seasonal and geographic variation in dietary composition was pervasive throughout our study. In the spring, we found salamanders from the western portion of our sampling range (SBI, EH, EW) did not differ in dietary prey composition, whereas those in the eastern portion of our sampling range (CF, SVF, CV) differed from most other sites (Fig. 2A). In the fall, we found that $\mathrm{EH}$ overlapped in dietary prey composition with SBI, EW, CV, and SVF, while SVF overlapped with $\mathrm{CF}, \mathrm{CV}$, and EW (Fig. 2B). The lack of a clear pattern across seasons suggests that the temporal availability of leaf litter invertebrate communities varies substantially across our study sites (Scott and Epstein, 1987; Walton, 2013). Relatively few studies have examined dietary variation in salamanders over temporal scales (but see Denoël et al., 2006; Wheeler et al., 2007; Sebastiano et al., 2012; Costa et al., 2015; Stuczka et al., 2016). It is possible that seasonal fluctuations impact the competitive environment. For instance, individuals in SBI and EW in the spring consumed a subset of available leaf litter invertebrates, whereas in the fall we found no evidence of prey differentiation. Our study sites were selected based on patterns of morph frequency variation and were distributed over a $120 \mathrm{~km}$ transect that contains many other populations that vary in morph ratios (Hantak et al., 2019). Thus, it is possible for site specific patterns to differ; however, our principal finding is that diet is variable across seasons and populations, and thus we caution against treating dietary differences and feeding ecology as regional, morph-specific, or species-level traits.

\section{DATA ACCESSIBILITY}

Supplemental material is available at https://www. copeiajournal.org/ce-19-264.

\section{ACKNOWLEDGMENTS}

We thank O. Brooks for help with data collection and $\mathrm{K}$. Williams for statistical advice. Funding was provided to M.M.H. from the Society for the Study of Amphibians and Reptiles (Grants in Herpetology), the Ohio Biological Survey, and Ohio University. Permission was granted to conduct this project at East Harbor State Park, Manatoc Scout Reservation, the Heineman property (SBI), Chapin Forest Reservation (permit \#2014-01), Squire Valleevue Farm, and Edison Woods Metropark. Research was conducted under Ohio University IACUC 12-L-050 and John Carroll University IACUC 1302.

\section{LITERATURE CITED}

Acord, M. A., C. D. Anthony, and C. M. Hickerson. 2013. Assortative mating in a polymorphic salamander. Copeia 2013:676-683.

Adams, D. C. 2000. Divergence of trophic morphology and resource use among populations of Plethodon cinereus and $P$. hoffmani in Pennsylvania, p. 383-394. In: The Biology of Plethodontid Salamanders. R. C. Bruce, R. G. Jaeger, and L. D. Houck (eds.). Springer, Boston. 
Adams, D. C. 2010. Parallel evolution of character displacement driven by competitive selection in terrestrial salamanders. BMC Evolutionary Biology 10:72.

Adams, D. C., M. E. West, and M. L. Collyer. 2007. Location-specific sympatric morphological divergence as a possible response to species interactions in West Virginia Plethodon salamander communities. Journal of Animal Ecology 76:289-295.

Anderson, M. J. 2006. Distance-based tests for homogeneity of multivariate dispersions. Biometrics 62:245-253.

Anderson, M. T., and A. Mathis. 1999. Diets of two sympatric neotropical salamanders, Bolitoglossa mexicana and $B$. rufescens, with notes on reproduction for $B$. rufescens. Journal of Herpetology 33:601-607.

Anthony, C. D., K. Jaworski, M. Messner, and C. M. Hickerson. 2017. Differences in prey availability within the territories of striped and unstriped Eastern Red-backed Salamanders (Plethodon cinereus). Herpetological Review 48: 509-514.

Anthony, C. D., and R. A. Pfingsten. 2013. Eastern Redbacked Salamander. Plethodon cinereus (Green 1818), p. 335-360. In: Amphibians of Ohio. R. A. Pfingsten, J. G. Davis, T. O. Matson, G. J. Lipps, D. Wynn, and B. J. Armitage (eds.). Ohio Biological Survey Bulletin New Series, Vol. 17, No. 1.

Anthony, C. D., M. D. Venesky, and C. M. Hickerson. 2008. Ecological separation in a polymorphic terrestrial salamander. Journal of Animal Ecology 77:646-653.

Bondi, C. A., C. M. Beier, M. K. Fierke, and P. K. Ducey. 2019. The role of feeding strategy in the tolerance of a terrestrial salamander (Plethodon cinereus) to biogeochemical changes in northern hardwood forests. Canadian Journal of Zoology 97:281-293.

Bondi, C. A., S. Green, and C. M. Beier. 2015. Evaluation of gastric lavage method for diet analysis of the Eastern Redbacked Salamander (Plethodon cinereus). Herpetological Review 46:196-199.

Brodie, E. D., Jr., B. J. Ridenhour, and E. D. Brodie III. 2002. The evolutionary response of predators to dangerous prey: hotspots and coldspots in the geographic mosaic of coevolution between garter snakes and newts. Evolution 56:2067-2082.

Burton, T. M. 1976. An analysis of the feeding ecology of salamanders (Amphibia, Urodela) of the Hubbard Brook Experimental Forest, New Hampshire. Journal of Herpetology 10:187-204.

Comendant, T., B. Sinervo, E. I. Svensson, and J. Wingfield. 2003. Social competition, corticosterone and survival in female lizard morphs. Journal of Evolutionary Biology 16:948-955.

Corl, A., A. R. Davis, S. R. Kuchta, and B. Sinervo. 2010. Selective loss of polymorphic mating types is associated with rapid phenotype evolution during morphic speciation. Proceedings of the National Academy of Sciences of the United States of America 107:4254-4259.

Cosentino, B. J., J.-D. Moore, N. E. Karraker, M. Ouellet, and J. P. Gibbs. 2017. Evolutionary response to global change: climate and land use interact to shape color polymorphism in a woodland salamander. Ecology and Evolution 7:5426-5434.

Costa, A., S. Salvidio, M. Posillico, G. Matteucci, B. De Cinti, and A. Romano. 2015. Generalisation within specialization: inter-individual diet variation in the only specialized salamander in the world. Scientific Reports 5: 13260.

Davis-Rabosky, A. R., C. L. Cox, and D. L. Rabosky. 2016. Unlinked Mendelian inheritance of red and black pigmentation in snakes: implications for Batesian mimicry. Evolution 70:944-953.

Deitloff, J., J. D. Peterson, and D. C. Adams. 2013. Complex species interactions lead to unpredictable outcome in Plethodon. Herpetologica 69:1-10.

Denoël, M., H. H. Whiteman, and S. A. Wissinger. 2006. Temporal shift of diet in alternative cannibalistic morphs of the tiger salamander. Biological Journal of the Linnean Society 89:373-382.

Dunham, A. E. 1983. Realized niche overlap: resource abundance and intensity of inter-specific competition, $\mathrm{p}$. 261-280. In: Lizard Ecology: Studies of a Model Organism. R. B. Huey, E. R. Pianka, and T. Shoener (eds.). Harvard University Press, Cambridge, Massachusetts.

Evans, A. E., B. R. Forester, E. L. Jockusch, and M. C. Urban. 2018. Salamander morph frequencies do not evolve as predicted in response to 40 years of climate change. Ecography 41:1687-1697.

Fisher-Reid, C. M., T. N. Engstrom, C. A. Kuczynski, P. R. Stephens, and J. J. Wiens. 2013. Parapatric divergence of sympatric morphs in a salamander: incipient speciation on Long Island? Molecular Ecology 22:4681-4694.

Ford, E. B. 1945. Polymorphism. Biological Review 20:73-88.

Gabor, C. R. 1995. Correlational test of Mathis' hypothesis that bigger salamanders have better territories. Copeia 1995:729-735.

Gibbs, J. P., and N. E. Karraker. 2006. Effects of warming conditions in eastern North American forests on RedBacked Salamander morphology. Conservation Biology 20: 913-917.

Grant, A. H., T. S. Ransom, and E. B. Liebgold. 2018. Differential survival and the effects of predation on a color polymorphic species, the Red-backed Salamander (Plethodon cinereus). Journal of Herpetology 52:127-135.

Grant, P. R., and B. R. Grant. 2006. Evolution of character displacement in Darwin's Finches. Science 313:224-226.

Gray, S. M., and J. S. McKinnon. 2007. Linking color polymorphism maintenance and speciation. Trends in Ecology \& Evolution 22:71-79.

Hantak, M. M., and S. R. Kuchta. 2018. Predator perception across space and time: relative camouflage in a colour polymorphic salamander. Biological Journal of the Linnean Society 123:21-33.

Hantak, M. M., S. R. Kuchta, C. M. Hickerson, and C. D. Anthony. 2015. Plethodon cinereus: morphology. Herpetological Review 46:409-410.

Hantak, M. M., R. B. Page, P. E. Converse, C. D. Anthony, C. M. Hickerson, and S. R. Kuchta. 2019. Do genetic structure and landscape heterogeneity impact color morph frequency in a polymorphic salamander? Ecography 42: 1383-1394.

Hantak, M. M., D. J. Paluh, and C. M. Hickerson. 2016. Comparison of the diets of sympatric erythristic and striped morphs of Plethodon cinereus (Eastern Red-backed Salamander). Northeastern Naturalist 23:219-228.

Highton, R. 1959. The inheritance of the color phases of Plethodon cinereus. Copeia 1959:33-37. 
Highton, R. 1975. Geographic variation in genetic dominance of the color morphs of the red-backed salamander, Plethodon cinereus. Genetics 80:363-374.

Holmes, I. A., M. R. Grundler, and A. R. Davis-Rabosky. 2017. Predator perspective drives geographic variation in frequency-dependent polymorphism. American Naturalist 190:E78-E90.

Ivanov, K., and J. Keiper. 2009. Effectiveness and biases of Winkler litter extraction and pitfall trapping for collecting ground-dwelling ants in northern temperate forests. Environmental Entomology 38:1724-1736.

Jaeger, R. G. 1980. Fluctuations in prey availability and food limitation for a terrestrial salamander. Oecologia 44:335341.

Jaeger, R. G. 1990. Territorial salamanders evaluate size and chitinous content of arthropod prey, p. 111-126. In: Behavioral Mechanisms of Food Selection. R. N. Hughes (ed.). NATO ASI Series, Subseries G. Ecological Sciences. Springer-Verlag, Heidelberg.

Jaeger, R. G., and D. E. Barnard. 1981. Foraging tactics of a terrestrial salamander: choice of diet in structurally simple environments. American Naturalist 117:639-664.

Jaeger, R. G., R. G. Joseph, and D. E. Barnard. 1981. Foraging tactics of a terrestrial salamander: sustained yield in territories. Animal Behaviour 29:1100-1105.

Jaworski, K. E., M. S. Lattanzio, C. M. Hickerson, and C. D. Anthony. 2018. Male mate preference as an agent of fecundity selection in a polymorphic salamander. Ecology and Evolution 8:8750-8760.

Karpestam, E., and A. Forsman. 2011. Dietary differences among colour morphs of pygmy grasshoppers revealed by behavioral experiments and stable isotopes. Evolutionary Ecology Research 13:461-477.

Kraemer, A. C., and D. C. Adams. 2013. Predator perception of Batesian mimicry and conspicuousness in a salamander. Evolution 68:1197-1206.

Legler, J. M., and L. J. Sullivan. 1979. The application of stomach-flushing to lizards and anurans. Herpetologica 35: 107-110.

Losos, J. B. 1990. A phylogenetic analysis of character dis placement in Caribbean Anolis lizards. Evolution 44:11891203.

Lotter, F., and N. J. Scott, Jr. 1977. Correlation between climate and distribution of the color morphs of the salamander Plethodon cinereus. Copeia 1977:681-690.

Maerz, J. C., J. M. Karuzas, D. M. Madison, and B. Blossey. 2005. Introduced invertebrates are important prey for a generalist predator. Diversity and Distributions 11:82-90.

Martinez, A. P. 2019. pairwiseAdonis: pairwise multilevel comparison using adonis. R package version 0.3 .

Mathis, A. 1990. Territoriality in a terrestrial salamander: the influence of resource quality and body size. Behaviour 112: 162-175.

Mathis, A. 1991. Territories of male and female terrestrial salamanders: costs, benefits, and intersexual spatial associations. Oecologia 86:433-440.

McKinnon, J. S., and M. R. Pierotti. 2010. Colour polymorphism and correlated characters: genetic mechanisms and evolution. Molecular Ecology 19:5101-5125.

McLean, C. A., and D. Stuart-Fox. 2014. Geographic variation in animal colour polymorphisms and its role in speciation. Biological Review 89:860-873.
Moore, J.-D., and M. Ouellet. 2014. A review of colour phenotypes of the Eastern Red-backed Salamander, Plethodon cinereus, in North America. Canadian Field-Naturalist 128:250-259.

Moore, J.-D., and M. Ouellet. 2015. Questioning the use of an amphibian colour morph as an indicator of climate change. Global Change Biology 21:566-571.

Moreno, G. 1989. Behavioral and physiological differentiation between the color morphs of the salamander, Plethodon cinereus. Journal of Herpetology 23:335-341.

ODNR (Ohio Department of Natural Resources). 2019. Soil regions. ODNR Department of Agriculture. Available at: www.agri.ohio.gov. Accessed 2 May 2019.

Oksanen, J., F. G. Blanchet, R. Kindt, P. Legendre, P. R. Minchin, R. B. O'Hara, G. L. Simpson, P. Solymos, M. H. H. Stevens, and H. Wagner. 2016. vegan: community ecology package. R package version 2.5-4. https://cran.rproject.org/package=vegan

Otaibi, B. W., Q. K. Johnson, and B. J. Cosentino. 2017. Postautotomy tail movement differs between colour morphs of the red-backed salamander (Plethodon cinereus). Amphibia-Reptilia 38:395-399.

Paluh, D. J., C. Eddy, K. Ivanov, C. M. Hickerson, and C. D. Anthony. 2015. Selective foraging on ants by a terrestrial polymorphic salamander. American Midland Naturalist 174:265-277.

Petranka, J. W. 1998. Salamanders of the United States and Canada. Smithsonian Press, Washington, D.C.

Petruzzi, E. E., P. H. Niewiarowski, and F. B. G. Moore. 2006. The role of thermal niche selection in maintenance of a colour polymorphism in redback salamanders (Plethodon cinereus). Frontiers in Zoology 5:3-10.

Pianka, E. R. 1974. Niche overlap and diffuse competition. Proceedings of the National Academy of Sciences of the United States of America 71:2141-2145.

Powell, R., J. S. Parmerlee Jr., M. A. Rice, and D. D. Smith. 1990. Ecological observations of Hemidactylus brookii haitianus Meerwarth (Sauria: Gekkonidae) from Hispaniola. Caribbean Journal of Science 26:67-70.

Price, T. 1987. Diet variation in a population of Darwin's Finches. Ecology 68:1015-1028.

R Core Team. 2018. R: a language and environment for statistical computing. R Foundation for Statistical Computing, Vienna, Austria. https://www.R-project.org/

Reiter, M. K., C. D. Anthony, and C. M. Hickerson. 2014. Territorial behavior and ecological divergence in a polymorphic salamander. Copeia 2014:481-488.

Schluter, D., and J. D. McPhail. 1992. Ecological character displacement and speciation in sticklebacks. American Naturalist 140:85-108.

Schoener, T. W. 1970. Size patterns in West Indian Anolis lizards. II. Correlations with the size of particular sympatric species-displacement and convergence. American Naturalist 104:155-174.

Scott, J. A., and M. E. Epstein. 1987. Factors affecting phenology in a temperature insect community. American Midland Naturalist 117:103-118.

Sebastiano, S., R. Antonio, O. Fabrizio, O. Daria, and M. Roberta. 2012. Different season, different strategies: feeding ecology of two syntopic forest-dwelling salamanders. Acta Oecologica 43:42-50. 
Sinervo, B., and E. Svensson. 2002. Correlational selection and the evolution of genomic architecture. Heredity 89: 329-338.

Stuczka, A., C. M. Hickerson, and C. D. Anthony. 2016. Niche partitioning along the diet axis in a colour polymorphic population of Eastern Red-backed Salamanders, Plethodon cinereus. Amphibia-Reptilia 37:283-290.

Svensson, E. I., B. Sinervo, and T. Comendant. 2001. Density-dependent competition and selection on immune function in genetic lizard morphs. Proceedings of the National Academy of Sciences of the United States of America 98:12561-12565.

Thompson, J. N. 2005. Coevolution: the geographic mosaic of coevolutionary arms races. Current Biology 15:992-994.

Venesky, M. D., and C. D. Anthony. 2007. Antipredator adaptations and predator avoidance by two color morphs of the eastern red-backed salamander, Plethodon cinereus. Herpetologica 63:450-458.
Venesky, M. D., A. Hess, J. A. DeMarchi, A. Weil, J. Murone, C. M. Hickerson, and C. D. Anthony. 2015. Morphspecific differences in disease prevalence and pathogeninduced mortality in a terrestrial polymorphic salamander. Journal of Zoology 295:279-285.

Walton, B. M. 2013. Top-down regulation of litter invertebrates by a terrestrial salamander. Herpetologica 69:127146.

West-Eberhard, M. J. 1986. Alternative adaptations, speciation, and phylogeny (a review). Proceedings of the National Academy of Sciences of the United States of America 83:1388-1392.

Wheeler, C. A., N. E. Karraker, H. H. Welsh, Jr., and L. M. Ollivier. 2007. Diet of the Del Norte Salamander (Plethodon elongatus): differences by age, gender, and season. Northwestern Naturalist 88:85-94. 